\title{
A muscle spindle model and study the effects of static and dynamic $y$ stimulations on primary and secondary ending outputs
}

\author{
Glayol Nazari Golpayegani ${ }^{1}$, Amir Homayoun Jafari ${ }^{1}$
}

${ }^{1}$ Biomedical Engineering Department Islamic Azad University, Science and Research Branch Tehran, Iran
Email: Gelayol777@yahoo.com, Amir j73@yahoo.com

Received 31 October 2008; revised 6 January 2009; accepted 19 January 2009.

\begin{abstract}
A linear lumped-parameter mechanical model of the muscle spindle is presented. It is shown that the model simulation exhibits the spindle behavior in most aspects of transient ramp-stretch performance. The requirements that such a model places on the mechanisms of fusimotor control are discussed. Then the efficacy of static $Y$ and dynamic $Y$ stimulation on primary ending output and secondary ending output is studied. The results of simulations show that primary ending of muscle spindle is affected either by static and dynamic stimulation and Secondary ending of muscle spindle is affected only by static fiber stimulation. The bias of primary ending output is increased by an increase in static $y$ stimulation. The Ramp of primary ending response is increased by an increase in dynamic $Y$ stimulation. An increase in static $Y$ stimulation in secondary ending of muscle spindle increases the dc level of secondary ending output so the bias of output is increased too.
\end{abstract}

Keywords: Modeling; Muscle Spindle; Postural Control Systems

\section{INTRODUCTION}

The mammalian muscle spindle, as recent anatomical studies have shown $[1,2,3,4,5]$, is a highly complex sensory organ connected in parallel with skeletal muscles for detecting change and rate of change in length in those muscles. Each spindle consists of several "interfusal" fibers (as distinct from "extrafusal" fibers of which the bulk of skeletal muscle consists) which appear to fall into two groups, with respect to their anatomical and their physiological characteristics. A simple example is illustrated in Figure 1. The larger type of fiber consists of striated contractile tissue with a non contractile equatorial region which possesses nuclei but lacks myofilaments. The distribution of nuclei within the equatorial region has led to naming this type the "nuclear-bag fiber." The smaller fibers have striations and nuclei throughout their entire length and are called "nuclearchain fibers."

The efferent innervation to the fibers is by way of the gamma-motor ( $\gamma$-motor) or fusimotor system. It is agreed that there are two anatomically distinct kinds of fusimotor innervation, distinguishable by the nature of the nerve endings. There are " $\gamma$-plate" fibers, ending in small end plates similar to those at extrafusal myoneural junctions and " $\gamma$-trail" fibers whose endings are more diffuse. (There is actually a third kind of innervation, the $\beta$-plate ending, which we will not discuss here). It is not agreed as to whether both types of endings are found on both bag and chain fibers, as Barker [1] holds. According to Boyd [2], plates are only found on bag fibers and trail only on chain fibers.

Activation of skeletal muscle has definite influence in increasing the stiffness and viscosity of the muscle [7]. In all likelihood, this happens to intrafusal muscles too, although it has not been verified experimentally. Such changes in parameter value would modify spindle response to stretch.

The amount of force produced by intrafusal contraction is known only roughly by measurement $[8,9]$ or computation $[10,11]$, and those measurements are of whole spindles without differentiation between bag or chain fiber contraction. Boyd has stated $[12,13]$ that contraction is more pronounced and faster in chain fibers than in bag fibers but much remains to be learned about this aspect of spindle behavior. The very tentative conclusion that has been proposed [14] is that dynamic stimulation controls output mainly through modification of parameter values by trail endings, while static stimulation works through force generated in the chain fibers through the plate endings.

The afferent innervation from the spindles is also of two types. The primary afferent has its endings both on the nuclear bag and on the nuclear chain. The secondary 
afferent usually has endings only on the nuclear chain. When the muscle is stretched or the y-motor nerves stimulated, action potentials are recorded in the primary and secondary afferent nerves. Corresponding to the anatomical observations described above, there is an equally bimodal response with respect to both stretch and stimulation as recorded from the two types of nerves.

The purpose of this paper is to describe some simulations of a linear lumped-parameter mechanical model of the muscle spindle as a neurally controlled transducer of stretch and discuss the requirements such a model places on the mechanisms of control. To do this, we shall first summarize the various types of responses to the various types of inputs that have been described by numerous previous investigators $[15,16,17,18]$.

In order to clarify our terminology yet remain reasonably consistent with the physiological literature, let us define three terms: dynamic sensitivity, static sensitivity, and bias. These refer to steady-state behavior after transients have died out. The dynamic sensitivity is a measure of that component of the spindle afferent output which is proportional to the rate of spindle stretch. It has units of $\mathrm{pps} / \mathrm{mm} / \mathrm{s}$. The static sensitivity is a measure of that component of the spindle afferent output which is proportional to the amplitude of spindle stretch. It has units of pps $/ \mathrm{mm}$. The bias is the tonic component of the spindle output that is independent of stretch. It has units of pps. Note that the bias corresponds to they intercept on the length-firing rate curve and, as such, it is sensitive to changes in the slope of that curve. Thus changes in the static sensitivity may be reflected, in part, by proportional changes in bias.
The $\gamma$-motor system can be divided into two groups, dynamic and static fusimotor fibers, on the basis of their differential effects on the primary and secondary afferents. These effects are summarized in Table I. The primary afferent is influenced by stimulation of both dynamic an static fibers, the former having their most pronounced effect on the dynamic sensitivity and the latter enhancing the bias and static sensitivity. The secondary afferent is influenced almost solely by the static fusimotor fibers.

This paper is organized as following sections: we describe our model in Section 2. We show our simulation results in Section 3. In Section 4 we study the effects of static $\gamma$ and dynamic $\gamma$ stimulation on primary ending output and secondary ending output and we have discussion in last section.

\section{MODEL}

The model we have chosen for our simulation is shown in Figure 2. It is an extremely general viscoelastic system for which we wish to establish, not merely a transfer function of the spindle, but an anatomical-topological equivalence such that displacements of the model nodes give a direct quantitative measure of deformations of the spindle's sensory regions.

The upper half of Figure 2 is the nuclear-bag fiber which consists of a lumped tendon and series elasticity, two identical contractile sections representing the larger intrafusal muscle fibers, and a non contractile nuclear bag from which part of the primary output is taken. The nuclear chain fiber is the lower half of the figure is at-

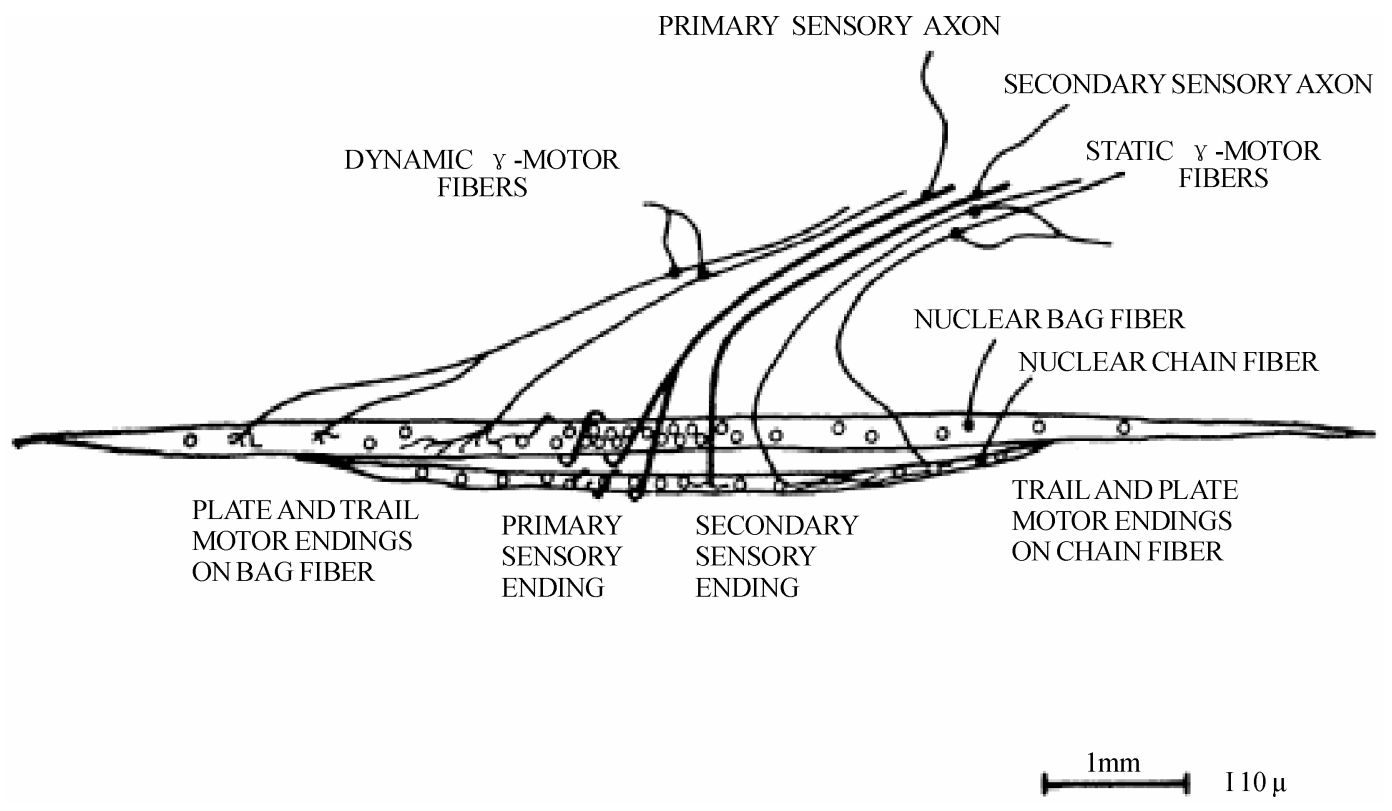

Figure 1. Simple two-fiber mammalian muscle spindle with two types of fibers and efferent and afferent innervation. 


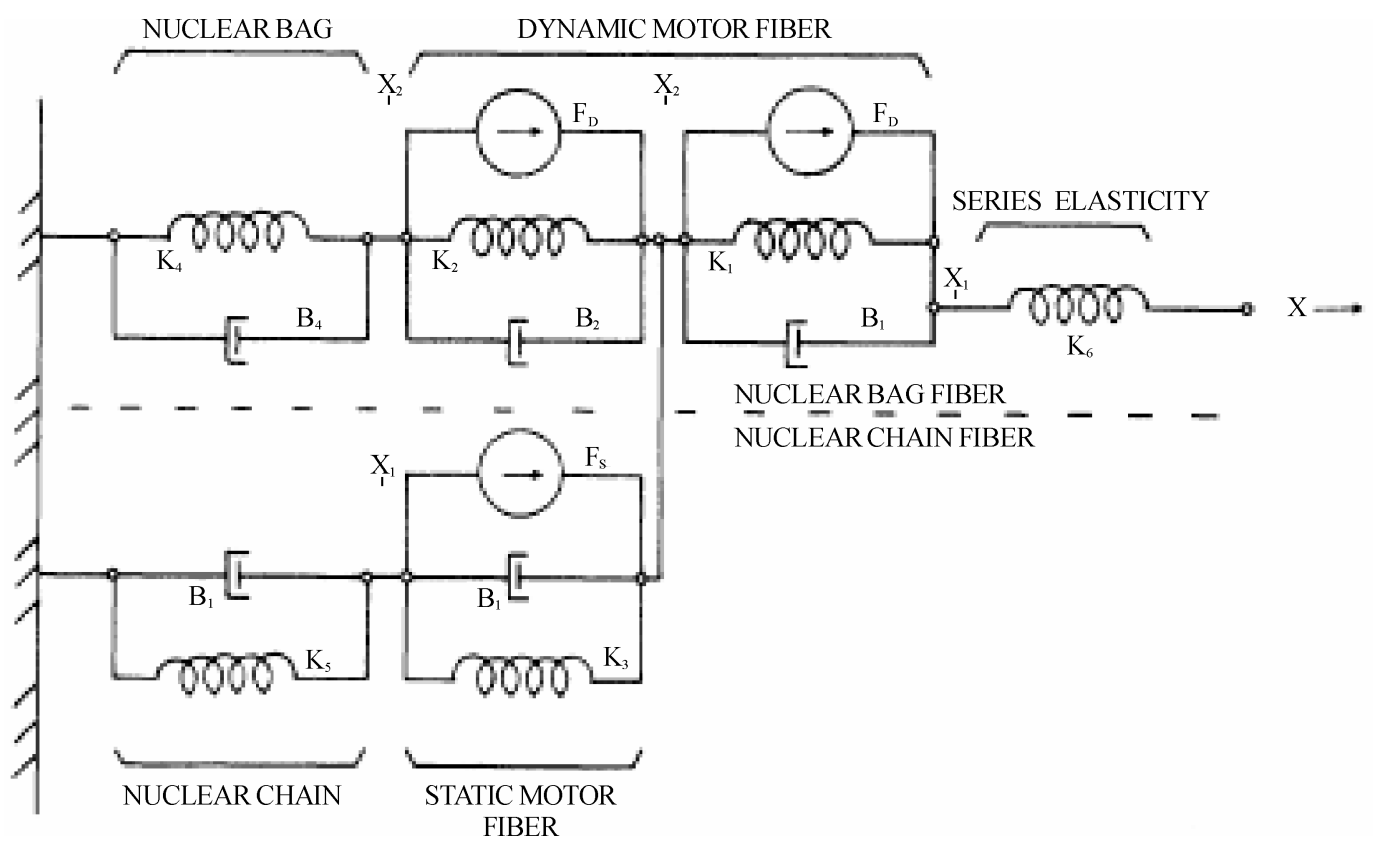

Figure 2. Mechanical model of simple mammalian muscle spindle.

tached to the bag fiber at the mid point between the two contractile sections. It has its own independent con-tractile section and a non contractile sensory segment. This segment provides the other portion of the primary output and all of the secondary output.

Before discussion of our simulations on this system, it would be of value to consider, in qualitative terms, the properties of the system that are important in duplicating spindle behavior. As was pointed out by Crowe and Matthews [18] and demonstrated in previous simulations $[11,19]$, the velocity sensitivity of the bag fiber can be accounted for by assuming that it is considerably stiffer elastically than the contractile tissue. The chain fiber, on the other hand, appears fairly uniform in composition. In terms of the model, it is convenient to talk in terms of a time constant. This time constant is defined by Eq.1:

$$
T_{i}=B_{i} / K_{i}
$$

The model response to stretch would be appropriate if the time constant of the bag T4 were to be much smaller than that of the muscular segments $\mathrm{T} 1$ and $\mathrm{T} 2$ while the two chain time constants T3 and T5 were to be of equivalent magnitudes to each other.

When stimulation is introduced, the three measures of spindle response discussed previously, namely, bias, static sensitivity, and dynamic sensitivity, are useful to systematize the discussion. Only the contractile segments are assumed controllable with respect to force output and parameter changes.

The system may be represented by linear differential equations as

$$
\begin{gathered}
K_{6}\left(x-x_{1}\right)=K_{1}\left(x_{1}-x_{2}\right)+B_{1}\left(\dot{x}_{1}+\dot{x}_{2}\right)+F_{D} \\
K_{6}\left(x-x_{1}\right)=K_{2}\left(x_{2}-x_{3}\right)+K_{3}\left(x_{2}-x_{4}\right)+B_{2}\left(\dot{x}_{2}+\dot{x}_{3}\right) \\
+B_{3}\left(\dot{x}_{2}-\dot{x}_{4}\right)+F_{D}+F_{S} \\
K_{2}\left(x_{2}-x_{3}\right)+B_{2}\left(\dot{x}_{2}-\dot{x}_{3}\right)+F_{D}=K_{4} x_{3}+B_{4} \dot{x}_{3} \\
K_{3}\left(x_{2}-x_{4}\right)+B_{3}\left(\dot{x}_{2}-\dot{x}_{4}\right)+F_{S}=K_{5} x_{4}+B_{5} \dot{x}_{4}
\end{gathered}
$$

A set of nonlinear equations in which the elasticities and viscosities are dependent on length and/or velocity were deliberately not used because, as we shall show, almost all the qualitative features of spindle response can be simulated without the vast increase in computational complexity required for such a nonlinear model. An important complicating feature we do require however, is that the intrafusal muscular components $\mathrm{K} 1, \mathrm{~K} 2, \mathrm{~K} 3$ and $\mathrm{Bi}, \mathrm{B} 2, \mathrm{~B} 3$ vary with the level of $\gamma$ control. In order to avoid the need for time varying parameters, we restricted the inputs in a manner that when stretch and fusimotor inputs were both applied their respective transient responses did not overlap in time. In this manner, stretch would be applied only after the parameters had reached appropriate equilibrium levels for the degree of fusimotor stimulation. Since all the experimental data we found in the literature has been gathered under these same conditions this limitation is not severe at present.

Under the above constraints, we can take the Laplace transform of (2) and then rewrite them as in (3) for analog simulation: 


$$
\begin{gathered}
x_{1}=a_{1} \frac{x_{1}}{s}+a_{2} \frac{x_{2}}{s}+a_{3} \frac{x}{s}+a_{4} \frac{F_{D}}{s}+x_{2} \\
x_{2}=b_{1} \frac{x_{1}}{s}+b_{2} \frac{x_{2}}{s}+b_{3} \frac{x_{3}}{s}+b_{4} \frac{x_{4}}{s}+b_{5} \frac{x}{s}+b_{6} \frac{F_{D}}{s} \\
+b_{7} \frac{F s}{s}+b_{8} x_{3}+b_{9} x_{4} \\
x_{3}=c_{1} \frac{x_{2}}{s}+c_{2} \frac{x_{3}}{s}+c_{3} \frac{F_{D}}{s}+c_{4} x_{2} \\
x_{4}=d_{1} \frac{x_{2}}{s}+d_{2} \frac{x_{4}}{s}+d_{3} \frac{F s}{s}+d_{4} x_{2}
\end{gathered}
$$

We chose to rewrite (7) by combining it with (8) and (9) and get (10) (equations for $a i, b i, c i, d i$, and $e i$ in terms of the model parameters are listed in Appen$\operatorname{dix}$ I):

$$
\begin{aligned}
x_{2}= & e_{1} \frac{x_{1}}{s}+e_{2} \frac{x_{2}}{s}+e_{3} \frac{x_{3}}{s}+e_{4} \frac{x_{4}}{s} \\
& +e_{5} \frac{x}{s}+e_{6} \frac{F_{D}}{s}+e_{7} \frac{F_{S}}{s}
\end{aligned}
$$

The block simulation of these four Eqs.6, 8, 9, and 10 is shown in Figure 3. The output of Figure 3(c) is nuclear bag stretch and output of $\mathbf{3 ( d )}$ is nuclear chain stretch. The primary output is given by Eq.11 and the secondary output by Eq.12:

$$
\begin{gathered}
f_{1}=\alpha x_{3}+\beta x_{4} \\
f_{2}=\delta x_{4}
\end{gathered}
$$

\section{RESULTS OF SIMULATIONS}

Figure 4 shows some results of our simulations for pri- mary and secondary outputs. The parameters used in the simulation are listed in Appendix II.

In Figure 4(a) the primary output in response to stretch and $\gamma$ stimulation is shown. In the lower curve, the spindle is relaxed and unstretched for 0.5 second and then stretched $3 \mathrm{~mm}$ at $6 \mathrm{~mm} / \mathrm{s}$. The middle curve shows the effects of adding static $\gamma$-motor stimulation of 100 pps starting at $\mathrm{t}=0$ while the upper curve shows the effects of dynamic $\gamma$-motor stimulation of $100 \mathrm{pps}$. Quite clearly, dynamic stimulation effects dynamic and static sensitivity as well as bias by stretching the nuclear bag and by increasing the viscosity of the bag fiber's contractile components. The effects of static stimulation are simply increased bias and static sensitivity from the chain branches of the ending. Figure 4(b) shows the output of the secondary afferent for the same inputs. The absence of dynamic sensitivity and the ineffectiveness of dynamic stimulation are apparent. These curves show that our model does mimic spindle behavior in most aspects of transient ramp-stretch performance as listed in Table $\mathbf{1 .}$

\section{STUDY THE EFFECTS OF STATIC AND DYNAMIC GAMMA STIMULA- TION ON PRIMARY AND SECON- DARY ENDING OUTPUTS}

After we simulated our model, we studied the effects of static and dynamic $\gamma$ stimulation on primary and secondary ending outputs.

\subsection{Effects of Static and Dynamic y Stimu- lation on Primary Ending Output}

As we can see from Figure 4(a), with applying the dynamic $\gamma$ stimulation on primary ending, we have following results: 1) the ramp of primary ending response is increased, 2) the dc level is increased and 3) final with (a)

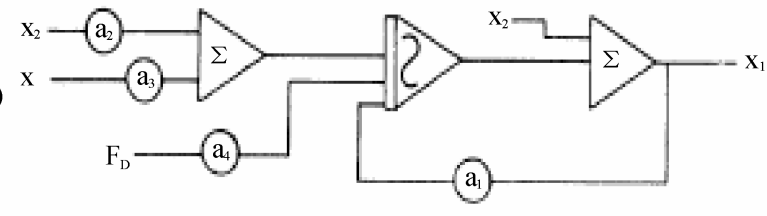

(b)

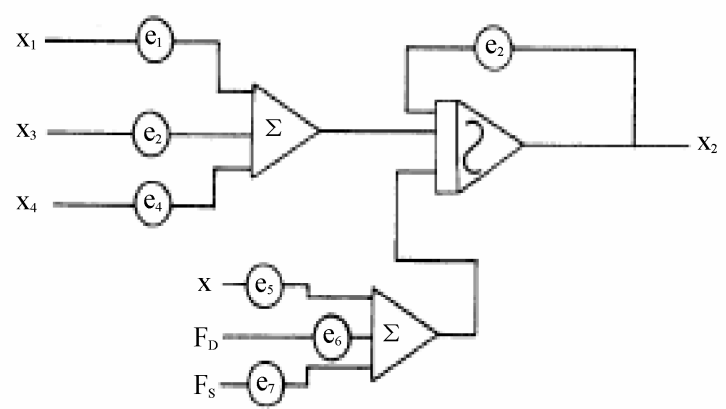

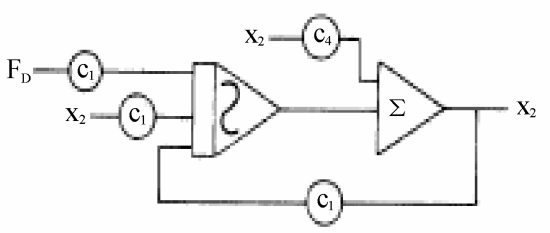

(c)

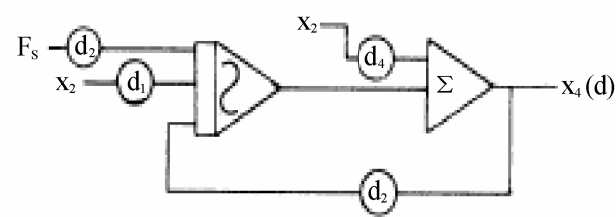

Figure 3. Analog computer simulation of model of Figure 2. 
unstimulated situation. With applying static $\gamma$ stimulation on primary ending output, dc level is increased and the ramp of primary ending output dose not change.

Briefly, we have following results for primary ending output with applying dynamic $\gamma$ stimulation: 1) the bias can be increased by either an increase in $\mathrm{k} 1, \mathrm{k} 2$, or output from the force generators FD. 2) Increased static sensitivity requires an increase in $\mathrm{k} 1, \mathrm{k} 2$. 3) Increased dynamic sensitivity requires an increase in $\mathrm{T} 1 / \mathrm{T} 4$ and T2/T4.

\subsection{Effects of Static and Dynamic y Stimu- lation on Secondary Ending Output}

As we can see from Figure 4(b), applying dynamic $\gamma$ stimulation, almost dose not have any clear effect on secondary ending output and it just increases the static sensitivity a little. With applying static $\gamma$ stimulation we have following results: 1) the dc level is increased, 2) the ramp of secondary ending response is not changed therefore the dynamic sensitivity is not increased and 3) the static sensitivity is highly increased.

Briefly, we have following results for secondary ending output with applying static $\gamma$ stimulation: 1) The bias is increased by an increase in $\mathrm{k} 3$ or output from the force generator Fs. 2) The static sensitivity is increased by an increase in k3. 3) The dynamic sensitivity is not significantly changed.
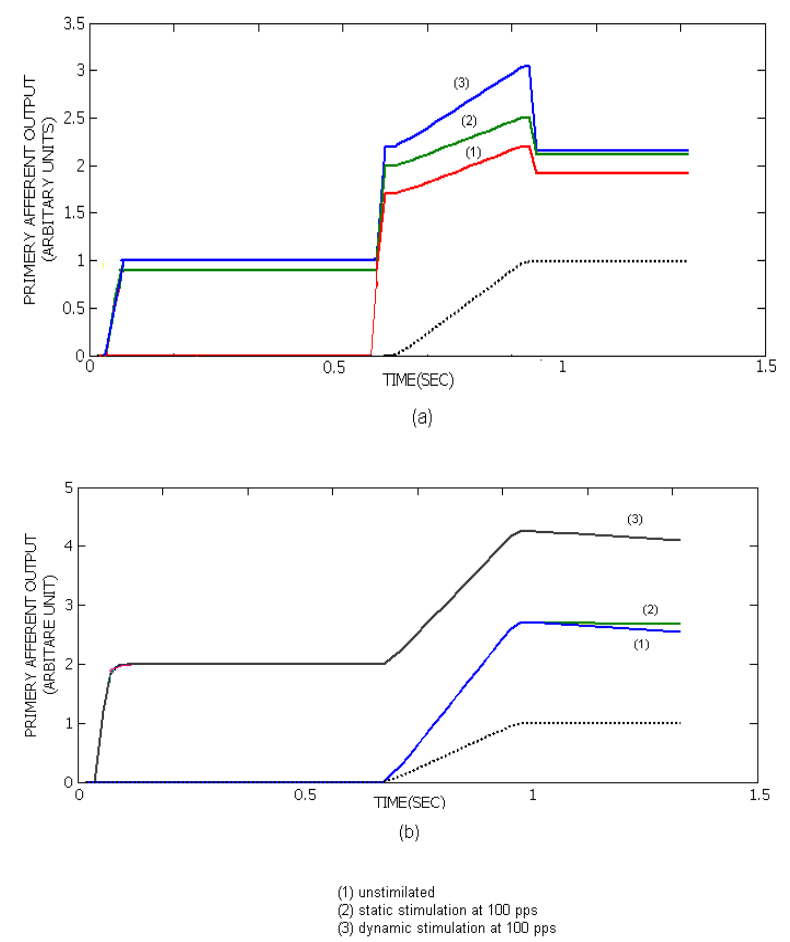

Figure 4. Stimulated response of a mammalian muscle spindle during stretch. (a) Primary ending. (b) Secondary ending.
Table 1. Effects of dynamic and static stimulation on bias and dynamic and static stimulation of spindle afferents.

\begin{tabular}{|c|c|c|c|}
\hline & Unstimulated & $\begin{array}{c}\text { Dynamic Fiber } \\
\text { Stimulation }\end{array}$ & $\begin{array}{l}\text { Static Fiber } \\
\text { Stimulation }\end{array}$ \\
\hline Primary ending & & & \\
\hline $\begin{array}{l}\text { Bias } \\
\text { Dynamic sensitivity } \\
\text { Static sensitivity }\end{array}$ & $\begin{array}{l}\text { variable } \\
\text { significant } \\
\text { significant }\end{array}$ & $\begin{array}{l}\text { increase } \\
\text { increase } \\
\text { slight increase }\end{array}$ & $\begin{array}{l}\text { large increase } \\
\text { decrease } \\
\text { increase }\end{array}$ \\
\hline $\begin{array}{l}\text { Secondary ending } \\
\text { Bias } \\
\text { Dynamic sensitivity } \\
\text { Static sensitivity }\end{array}$ & $\begin{array}{l}\text { variable } \\
\text { slight } \\
\text { significant }\end{array}$ & $\begin{array}{l}\text { no effect } \\
\text { no effect } \\
\text { no effect }\end{array}$ & $\begin{array}{l}\text { increase } \\
\text { no effect } \\
\text { increase }\end{array}$ \\
\hline
\end{tabular}

The effects of dynamic and static stimulation on bias and dynamic and static sensitivity of spindle afferent is listed in Table I. As we can see from Table I, primary ending is affected either by static and dynamic stimulation. Secondary ending is affected only by static fiber stimulation.

\subsection{Effects of an Increase in Dynamic $y$ Stimulation on Primary Ending Output}

Figure 5 shows the effect of an increase in dynamic $\gamma$ stimulation on primary ending output. Upper curve in Figure 5 (curve 2) shows the effect of an increase in dynamic $\gamma$ in compare with mid curve (curve 1) with no increase in dynamic $\gamma$ stimulation. As we can see from Figure 5, with applying an increase in dynamic $\gamma$ stimulation we observe that: 1) Ramp of primary ending response is increased, therefore dynamic sensitivity is increased too, 2) If we consider primary ending output as a step jump, the height of this step is increased with an increase in dynamic $\gamma, 3$ ) de level is not changed so we have no change in bias.

\subsection{Effects of an Increase in Static y Stimu- lation on Primary Ending Output}

Figure 6 shows the effect of an increase in static $\gamma$ stimulation on primary ending output. Upper curve (curve 2) in Figure 6 shows the primary ending output

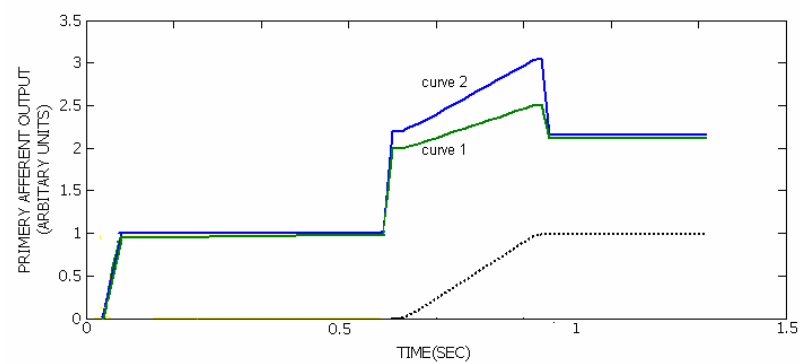

Figure 5. the effect of an increase in $\gamma \mathrm{d}$ stimulation on primary ending output. Primary ending output without any increase in $\gamma \mathrm{d}$ stimulation (curve 1) and primary ending output with an increase in $\gamma \mathrm{d}$ stimulation (curve 2). 
with applying an increase in static $\gamma$ stimulation and mid curve (curve 1) in Figure 6 shows primary ending output just with applying static $\gamma$ stimulation. As we can see from Figure 6, with applying an increase in $\gamma$ s stimulation, we observe that: 1) The ramp of primary ending response is not changed and as a result, the dynamic sensitivity is not change too. 2) dc level is increased and therefore the bias in increased just a little. 3) Static stimulation is increased just a little.

\subsection{Effects of an Increase in Static y Stimu- lation on Secondary Ending Output}

Figure 7 shows the effect of an increase in static $\gamma$ stimulation on secondary ending output. Upper curve (curve 2) in Figure 7 shows the secondary ending output with applying an increase in static $\gamma$ stimulation and mid curve (curve 1) in Figure 7 shows primary ending output just with applying static $\gamma$ stimulation. As we can see from Figure 6, with applying an increase in $\gamma$ stimulation, we observe that: 1) de level is increased so bias is increased too. 2) static stimulation is increased.

\section{DISCUSSION}

The greatest difficulty encountered in evaluating the model is quantifying the data on spindle behavior that are presented in the literature. We shall not dwell on that problem here but instead consider the consequences of our chosen model in terms of response to stretch and possible mechanisms of $\gamma$ control.

Since the model is linear, both primary and secondary steady-state outputs are proportional to the degree of stretch. The primary output is also linearly proportional to stretch velocity if the duration of stretch is not too brief. This is as it should be and is, in fact, the one common feature of the models that have appeared previously $[10,11,19,20,21,22]$.

The most interesting feature of the model however, is that it allows us to isolate the various effects of $\gamma$ stimulation. To begin with, it is clear that only effect dynamic or static force generators can have is to increase the bias of output. They provide an additive component to the output with no influence on either dynamic or static sensitivities.

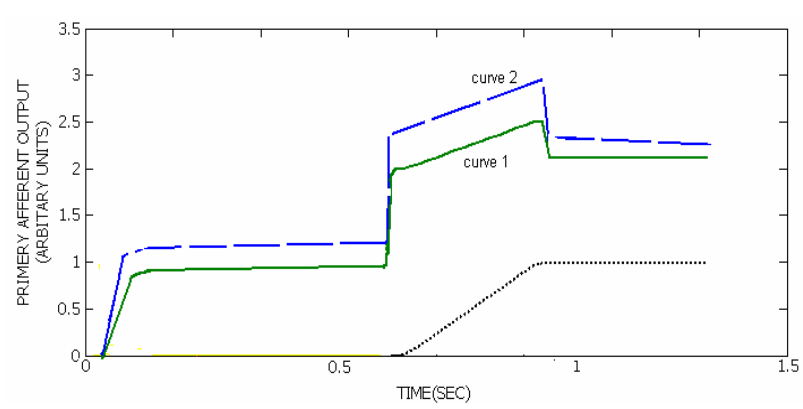

Figure 6. The effect of an increase in $\gamma \mathrm{s}$ stimulation on primary ending output.

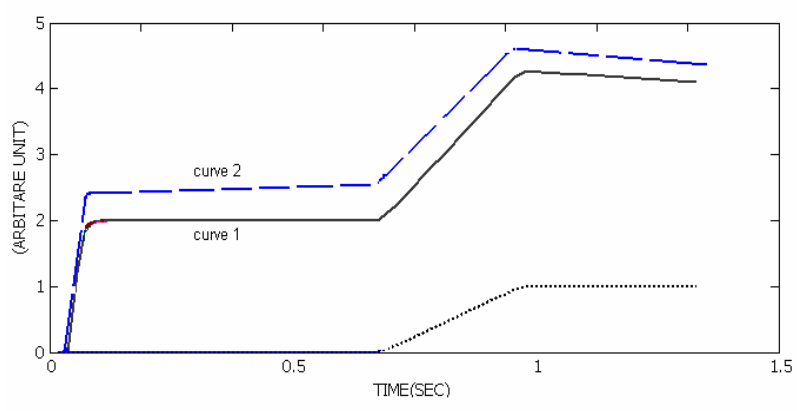

Figure 7. The effect of an increase in $\gamma \mathrm{s}$ stimulation on secondary ending output. Secondary ending output without any increase in $\gamma \mathrm{s}$ stimulation (curve 1) and secondary ending output with an increase in $\gamma$ s stimulation (curve 2).

The effects of parametric variation are more profound. The static sensitivity is a function solely of the elasticities and any variations in $K 1, K 2$, or $K 3$ by $\gamma$-efferent activity would appear there. Furthermore, if the spindle is maintained under some degree of passive stretch, an increase in the stiffness of the muscular elasticities will also appear as an increase in the bias, an increase proportional to the change in $\mathrm{K}$ and to the initial degree of stretch.

The dynamic sensitivities are more complicated functions of both the elasticities and viscosities but certain eneralizations can be made. In the bag fiber where T4< $\mathrm{T} 1, \mathrm{~T} 2$, changes in B1 and B2 will appear as almost proportional changes in primary dynamic sensitivity. By contrast, the dynamic sensitivity of the chain fiber will be only slightly influenced by changes in B1, B2, or B3. Changes in viscosity will not affect the output while the spindle length is constant.

It is instructive, too, to look at the actual degree of deformation of the sensory regions that is caused by stretching the spindle. In the unstimulated case, the peak extension which occurs in the sensory region of the chain fiber is 23 percent of the total spindle stretch. By contrast, the peak extension of the sensory region of the bag fiber is only 0.8 percent of the total stretch. The other 99.2 percent of the deformation occurs in the nonsensory elements. This fact is a direct consequence of the great stiffness of the bag's sensory area compared to the stiffness of the rest of the spindle.

These observations on model behavior suggest that the following conclusions may apply to the physiological spindle.

1) The control exerted by the dynamic $\gamma$ efferents on the dynamic behavior of the primary afferent may be through modification of the ratio of the viscosity of the nuclear bag to the viscosity of the bag's intrafusal musculature. This effect would be appeared independently of any force generation by the fiber nor would it be seriously affected by a simultaneous increase in muscle stiffness.

2) The control of the static $\gamma$ efferents on the static 
behavior of the two types of afferents may be, in part, modification of the elasticities of either the bag or the chain but may include a large degree of output from the forcegenerators.

3) The control of bias by the $\gamma$ efferents may be by intrafusal force generation but the existence of this control is open to question because changes in static sensitivity can appear as change in the bias of a stretched spindle.

4) The question of whether the bag fiber contracts in response to dynamic $\gamma$ stimulation will be difficult to resolve by direct visual observation because the bag is very stiff and deforms only slightly.

5) In light of the above, either of the theories of $y$-efferent innervation of the intrafusal fibers are acceptable. Even if both plate and trail endings are to be found on both bag and chain fibers, the distinguishing response of the bag fiber would be to only one type (the parametric modifier, presumably the trail ending) while the chain could respond to either or both types of innervation.

6) We should also recognize the fact that the dynamics displayed by the spindle and mimicked by the model are not really sufficiently complex to require a fourth-order transfer function. The purpose of this elaborate model we have presented is to maintain an equivalence between the spindle anatomy and the model topology, but as a black box, simpler models presented previously $[10,11]$, are quite adequate.

\section{REFERENCES}

[1] D. Barker, (2002) The motor ininervation of the mammalian muscle spindle, in Nobel Symposium Muscular Afterents and Motor Control, R. Granit, Ed. New York: Wiley.

[2] A. Boyd, (1996) The motor innervation of mammalian muscle spindles, J. Physiol. (London), 159.

[3] R. W. Banks, (2001) The tenuissiumus muscle of the cat, J. Physiol. (London), 133.

[4] D. Barker (1999) The innervation of mammalian neuro-mulscular spindles, J. Physiol. (London), 140.

[5] (2000) Simple and compound mammalian muscle spindles, J. Physiol. (London), 145.

[6] D. Barker and I. A. Boyd, (2004) in Nobel Symposium Muscular Afferents and Motor Control, R. Granit, Ed. New York: Wiley.

[7] G. C. Agarwal, B. M. Berman, and L. Stark, Studies in postural control systems, part 1: torque disturbance input, 6, 116-121.

[8] K. Diete-Spiff, (2001) Tension development by isolated muscle spindles of the cat, J. Physiol. (London), 193.

[9] K. Krnjevk and N. M. Van Gelder, (2002) Tension changes in crayfish stretch receptors, J. Physiol. (London), 159.

[10] G. C. Agarwal, G. L. Gottlieb, and L. Stark, (March 2004) Models of muscle proprioceptive receptors, presented at the University of Michigan-NASA Conf. Manual Control.

[11] G. L. Gottlieb, G. C. Agarwal, and L. Stark, (March 2003) Stretch receptor models, part I single-efferent single-afferent innervation, IEEE Trans. Man-Machine Systems, MMS-10, 17-27.

[12] A. Boyd, (2001) The behavior of isolated mammalian muscle spindles with intact innervation, J. Physiol. (London), 186.

[13] (2001) The mechanical properties of mammalian intrafusal muscle fibers, J. Physiol. (London), 187.

[14] P. Bessou and Y. Laporte, (2001) Observations on static fusimotor fibres, in Nobel Synmposium-Muscular Afferents and Motor Control, R. Granit, Ed. New York: Wiley.

[15] P. Bessou, Y. Laporte, and B. Pages, (2001) Similitude des effets (statiques ou dynamiques) exerces par des fibres fusimotrices le chat, J. Physiol, Paris, 58.

[16] B. Appelberg, P. Bessou, and Y. Laporte, (2001) Action of static and dynamic fusimotor fibres on secondary endings of cats' spindles, J. Physiol. (London), 185.

[17] E. Emonet-Denand, Y. Laporte, and B. Pages, (2001) Fibres fusimotrices statiques et fibres fusimotrices dynamiques chez le lapin, Arch. Ital. Biol., 104.

[18] Crowe and P. B. C. Matthews, (2003) The effects of stimulation of static and dynamic fusimotor fibres on the response to stretching of the primary endings of muscle spindles, J. Physiol. (London), 174.

[19] J. C. Houk, R. Cornew, and L. Stark, (2001) A model of adaptation in amphibian spindle receptors, J. Theoret. Biol., 12.

[20] Anndersson, G. Lennerstrand, and U. Thoden, Cat muscle spindle model, Dig. 1999 Internatl. Conf. on Medical and Biological Engineering (Stockholm).

[21] M. D. Angers, (2001) Model mecanique de fuseau neuromusculaire de-efferente: Terminaisons primaires et secondaires, Compt. Rend. Acad. Sci. (Paris), 261.

[22] Crowe, (2003) A mechanical model of the mammalian muscle spindle, J. Theoret. Biol., 21. 


\section{APPENDIX 1}

The following equations relate the block simulation parameters (Figure 3) to the model parameters (Figure 2) as determined by (3) and (4).

1) $a$ parameters:

$$
\begin{aligned}
& a_{1}=-\frac{K_{1}+K_{6}}{B_{1}}, a_{2}=\frac{K_{1}}{B_{1}} \\
& a_{3}=\frac{K_{6}}{B_{1}}, \quad a_{4}=-\frac{1}{B_{1}}
\end{aligned}
$$

2) c parameters:

$$
\begin{aligned}
& c_{1}=\frac{B_{2}}{B_{2}+B_{4}}, \quad c_{2}=\frac{K_{2}}{B_{2}+B_{4}} \\
& c_{3}=\frac{K_{2}+K_{4}}{B_{2}+B_{4}}, \quad c_{4}=\frac{1}{B_{2}+B_{4}}
\end{aligned}
$$

3) $d$ parameters:

$$
\begin{aligned}
& d_{1}=\frac{B_{3}}{B_{3}+B_{5}}, \quad d_{2}=\frac{K_{3}}{B_{3}+B_{5}} \\
& d_{3}=-\frac{K_{3}+K_{5}}{B_{3}+B_{5}}, \quad d_{4}=\frac{1}{B_{3}+B_{5}}
\end{aligned}
$$

4) $e$ parameters:

$$
\begin{aligned}
& e_{1}=-K_{6} H \\
& e_{2}=-\left[\frac{B_{4} K_{2}}{B_{2}+B_{4}}+\frac{B_{5} K_{3}}{B_{3}+B_{5}}\right] H \\
& e_{3}=\left[\frac{B_{4} K_{2}-B_{2} K_{4}}{B_{2}+B_{4}}\right] H, e_{4}=\left[\frac{B_{5} K_{3}-B_{3} K_{5}}{B_{3}+B_{5}}\right] H \\
& e_{5}=K_{6} H, \quad e_{6}=-\left[\frac{B_{4}}{B_{2}+B_{4}}\right] H
\end{aligned}
$$

$$
e_{7}=-\left[\frac{B_{5}}{B_{3}+B_{5}}\right] H
$$

where

$$
H=\frac{1}{\frac{B_{2} B_{4}}{B_{2}+B_{4}}+\frac{B_{3} B_{5}}{B_{3}+B_{5}}}
$$

\section{APPENDIX 2}

The following parameter values were used in the simulation shown in Figure 4:

$$
\begin{array}{ll}
K_{1}=0.02 & B_{1}=0.25 \\
K_{2}=0.02 & B_{2}=0.025 \\
K_{3}=0.03 & B_{3}=0.001 \\
K_{4}=4.0 & B_{4}=0.01 \\
K_{5}=0.03 & B_{5}=0.001 \\
K_{6}=2.0 & \\
f_{D}=\text { dynamic } & \gamma \text { firing rate } \\
f_{S}=\text { static } \gamma & \text { firing rate }
\end{array}
$$$$
\begin{aligned}
& \frac{\partial F_{D}}{\partial f_{D}}=0.0003, \quad \frac{\partial F_{S}}{\partial f_{S}}=0.0003 \\
& \frac{\partial K_{1}}{\partial f_{D}}=\frac{\partial K_{2}}{\partial f_{D}}=\frac{\partial B_{1}}{\partial f_{D}}=\frac{\partial B_{2}}{\partial f_{D}}=0.01 \\
& \frac{\partial K_{3}}{\partial f_{S}}=\frac{\partial B_{3}}{\partial f_{S}}=0.01
\end{aligned}
$$

$\alpha / \beta=30(\operatorname{see}(5)), K$ is given in $\mathrm{N} / \mathrm{m}$ and $B$ in $\mathrm{N} \cdot \mathrm{s} / \mathrm{m}$ 